\title{
REDUCED KINETICS AND COUPLING FUNCTIONS \\ FOR CALCULATING CO AND NO EMISSIONS \\ IN GAS-TURBINE COMBUSTION
}

\author{
ALAIN LÉPINETTE AMABLE LIÑÁN \\ BENIGNO LÁZARO ANTONIO L. SÁNCHEZ*
}

\section{INTRODUCTION}

The computation of numerous aspects of combustion, including in particular pollutant emissions, necessitates a realistic representation for the underlying chemistry. Reduced chemical-kinetic mechanisms, systematically deduced through introduction of steady states for intermediate species and partial equilibria for fast reverse reactions, are now widely used for an increasing number of applications, providing a reliable and yet sufficiently simple chemistry description that is able to reproduce the essential features of the combustion process over a wide range of conditions with a minimum computational effort (Peters and Rogg, 1993).

In recent efforts (Sánchez et al., 2000) to generate reduced chemistry descriptions for lean premixed (LP) and lean premixed prevaporized (LPP) combustion systems, we have investigated lean premixed flames at elevated pressure. The parametric range investigated includes pressures, $p$, initial reactant temperatures, $T_{u}$, and equivalence ratios, $\phi$, typical of gas-turbine combustors, that is, $p \gtrsim 5 \mathrm{bar}, T_{u} \gtrsim 500 \mathrm{~K}$, and $\phi \lesssim 1$. We have found that, under these conditions, the slow-CO-oxidation limit applies (Bui-Pham et al., 1992), and the chemistry description can be reduced to two global steps for hydrocarbon oxidation (partial hydrocarbon oxidation to give $\mathrm{CO}$ and $\mathrm{H}_{2} \mathrm{O}$ followed by slow $\mathrm{CO}$ oxidation to produce $\mathrm{CO}_{2}$ ) and an additional step for $\mathrm{NO}_{x}$ production. The resulting three-step mechanism is similar to that developed by other research groups ( $\mathrm{Li}$ et al., 1999), differences emerging only in the associated rate expressions. 
Results corresponding to methane laminar flames computed in (Sánchez et al., 2000), including freely propagating planar flames and adiabatic and nonadiabatic stretched flames, indicate that the proposed two-step fuel-oxidation chemistry describes with excellent accuracy many aspects of fuel-lean premixed combustion, including in particular flame propagation velocities, flame structures, strain-induced extinction, and emissions of $\mathrm{CO}$. The results also indicate that over a wide range of conditions the nitrogen chemistry is well described by the one-step scheme, which takes into account both the thermal and the nitrous oxide contributions to NO production.

The present paper uses the previously derived mechanism, which is briefly presented in the next section (see Sánchez et al. [2000] for a more detailed account of its derivation). A simplified formulation of the corresponding conservation equations for species and energy in terms of coupling functions is then derived. The resulting equations and boundary conditions, different in premixed and nonpremixed systems, can be used in direct numerical simulations (DNS) of complex, three-dimensional, unsteady flows. They also serve as a basis for the derivation with modeling of the equations for describing combustion in turbulent flows (for instance, in large eddy simulations using presumed probability density functions in the description of the subgrid fluctuations of main species and enthalpy). Validation of the reduced kinetics through comparisons with detailed-chemistry calculations of methane laminar flames is performed next. Results of freely propagating premixed flames supplementing those in Sánchez et al. (2000) are presented first. Then, the applicability of the mechanism to nonpremixed gas-turbine combustion is investigated through comparisons of preheated counterflow diffusion flames at elevated pressure. The results obtained are satisfactory for all flames, thereby validating the slow-CO-oxidation approximation used here and motivating further work on the subject.

\section{REDUCED KINETIC DESCRIPTION}

The detailed chemical description of the fuel-oxidation process of a given hydrocarbon $\mathrm{C}_{x} \mathrm{H}_{y}$ requires in general consideration of a large number of intermediate species and elementary rates. Reduced-chemistry techniques have been used in the past few years to reduce the needed chemical description to a few overall reactions (Peters and Rogg, 1993). The resulting global rates are given in terms of those of several rate-limiting 
elementary reactions through rationally derived expressions. Reduced chemical-kinetic mechanisms with different levels of complexity are now available for many fuels under different combustion conditions. While a single overall step $\mathrm{C}_{x} \mathrm{H}_{y}+(x+y / 4) \mathrm{O}_{2} \rightarrow x \mathrm{CO}_{2}+(y / 2) \mathrm{H}_{2} \mathrm{O}$ may be adequate for some applications, the description of many aspects of premixed and nonpremixed flames requires in general multiplestep mechanisms.

We are concerned here with the conditions typically found in gasturbine combustion. Because of the existing high pressure, a steady-state approximation provides sufficient accuracy almost everywhere for most relevant intermediates, an exception being carbon monoxide, whose oxidation rate is controlled by the relatively slow elementary reaction $\mathrm{CO}+\mathrm{OH} \stackrel{1}{\rightleftharpoons} \mathrm{CO}_{2}+\mathrm{H}$. Correspondingly, the fuel oxidation process is seen to occur in two steps, partial fuel oxidation to give $\mathrm{CO}$ and $\mathrm{H}_{2} \mathrm{O}$ according to the overall reaction

$$
\mathrm{C}_{x} \mathrm{H}_{y}+\left(\frac{x}{2}+\frac{y}{4}\right) \mathrm{O}_{2} \rightarrow x \mathrm{CO}+\frac{y}{2} \mathrm{H}_{2} \mathrm{O},
$$

followed by slow $\mathrm{CO}$ oxidation to give $\mathrm{CO}_{2}$, i.e.,

$$
\mathrm{CO}+\frac{1}{2} \mathrm{O}_{2} \rightleftharpoons \mathrm{CO}_{2} \text {. }
$$

Concentrations of intermediates other than $\mathrm{CO}$, to be computed from steady-state equations, are very small and contribute negligibly to the overall mass balance. The first reaction is fast and takes place in a very thin layer, while the second is slow and occurs in a distributed manner in a relatively large region. The resulting flame structures are different in premixed and nonpremixed systems. In the former, the fuel-consumption layer separates the frozen preheat region from the CO-oxidation region, while in diffusion flames the fuel-consumption layer separates the fuel and oxidizer sides of the flow field, $\mathrm{CO}$ oxidation occurring only on the oxidizer side where radicals exist in nonnegligible concentrations. Note that the mechanism I-II only describes $\mathrm{CO}$ emissions that are due to incomplete oxidation along the main chain. Carbon monoxide emissions due to soot oxidation, which can be significant in heavily sooting flames, are not considered in the present analysis.

In the region where $\mathrm{CO}$ is being oxidized, all intermediates closely follow a steady-state approximation. Correspondingly, the $\mathrm{CO}$-oxidation rate can be evaluated from the rate of the elementary reaction $\mathrm{CO}+\mathrm{OH} \stackrel{1}{\rightleftharpoons}$ 
$\mathrm{CO}_{2}+\mathrm{H}$ by using the steady-state expressions for the concentrations of $\mathrm{H}$ and $\mathrm{OH}$, a development presented below. A severe limitation of the proposed two-step mechanism concerns, however, the computation of the fuel-consumption rate. The steady-state assumptions for the different intermediates, which are excellent approximations in the CO-oxidation region, fail in the thin fuel-consumption layer. Since fuel consumption is mainly due to fuel attack by radicals, the rate of reaction I depends on the radical level in the fuel-consumption layer, which cannot be accurately computed from steady-state expressions.

This limitation can be overcome in different ways depending on the application. For instance, in nonpremixed flames far from extinction, the fuel-consumption rate is sufficiently fast that it can be assumed to be controlled by diffusion, as done for instance by Bollig et al. (1998) and also in the computations of diffusion flames performed below. On the other hand, for the turbulent premixed flames investigated in $\mathrm{Li}$ et al. (1999), fuel consumption was assumed to be controlled by turbulence, and was assigned a rate derived from a simple eddy-breakup model. An alternative recently used (Sánchez et al., 2000) entails the use of a heuristic Arrhenius law of the form

$$
\omega_{\mathrm{I}}=B Y_{\mathrm{F}}^{n} Y_{\mathrm{O}_{2}}^{m}\left(p / p_{o}\right)^{\beta} \exp \left(-T_{a} / T\right),
$$

which incorporates explicit dependences on the fuel and oxygen mass fractions, $Y_{\mathrm{F}}$ and $Y_{\mathrm{O}_{2}}$, pressure, $p$, and temperature, $T$. By appropriately choosing the different reaction-rate parameters $B, n, m, p_{o}, \beta$, and $T_{a}$, it is expected that the proposed empirical law be able to reproduce the rate of fuel consumption (and therefore the location of the fuel-consumption layer) in complex flow configurations. In the selection procedure, which is carefully explained by Sánchez et al. (2000), the different parameters are chosen to reproduce laminar flame propagation velocities under a wide range of conditions, as well as critical values of strain rates at extinction. Specific parametric values corresponding to methane combustion, to be employed in the calculations of premixed flames shown below, are $B=5.46 \times 10^{9}$ mole $\mathrm{cm}^{-3} \mathrm{~s}^{-1}, n=1, m=2.5, p_{o}=18$ bar, $\beta=0.5$, and $T_{a}=22850 \mathrm{~K}$.

As previously mentioned, all intermediates except $\mathrm{CO}$ maintain steady state in the CO-oxidation region. Explicit expressions for the concentrations

$$
[\mathrm{H}]=K_{3}\left[\mathrm{H}_{2}\right][\mathrm{OH}] /\left[\mathrm{H}_{2} \mathrm{O}\right]
$$


and

$$
[\mathrm{O}]=K_{4}[\mathrm{OH}]^{2} /\left[\mathrm{H}_{2} \mathrm{O}\right]
$$

follow from further assuming partial equilibria of reactions $\mathrm{H}_{2}+\mathrm{OH} \rightleftharpoons \mathrm{H}_{2} \mathrm{O}+\mathrm{H}$ and $\mathrm{OH}+\mathrm{OH} \rightleftharpoons \mathrm{H}_{2} \mathrm{O}+\mathrm{O}, K_{j}$ representing here equilibrium constants. As shown by Sánchez et al. (2000), the steadystate expression for $\mathrm{H}_{2}$ can be written as

$$
\left[\mathrm{H}_{2}\right]=K_{3}^{-1}\left[\mathrm{O}_{2}\right]^{-1} \alpha_{1}\left\{\left(K_{4} / K_{2}\right)[\mathrm{OH}]^{2}+\frac{1}{2}\left(k_{1 f} / k_{2 f}\right)[\mathrm{CO}]\left[\mathrm{H}_{2} \mathrm{O}\right]\right\},
$$

whereas the OH steady-state concentration is determined from the fourth-order polynomial

$$
a_{4}[\mathrm{OH}]^{4}+a_{3}[\mathrm{OH}]^{3}+a_{2}[\mathrm{OH}]^{2}+a_{1}[\mathrm{OH}]^{1}+a_{0}=0,
$$

where we have introduced the coefficients

$$
\begin{aligned}
& a_{4}=-\left(K_{4} k_{6 f} / K_{2}\right)\left[1-\alpha_{1}(1-\gamma)\right], \\
& a_{3}=-\left(K_{4} k_{5 b} / K_{2}\right)\left[1-\alpha_{1}\right][\mathbf{M}], \\
& a_{2}=\frac{1}{2} \alpha_{1}\left(k_{1 f} k_{6 f} / k_{2 f}\right)(1-\gamma)[\mathrm{CO}]\left[\mathbf{H}_{2} \mathrm{O}\right], \\
& a_{1}=\frac{1}{2} \alpha_{1}\left(k_{1 f} k_{5 b} / k_{2 f}\right)[\mathbf{M}][\mathrm{CO}]\left[\mathbf{H}_{2} \mathrm{O}\right], \\
& a_{0}=\left(k_{5 b} k_{6 b} / k_{2 f}\right)[\mathbf{M}]\left[\mathbf{H}_{2} \mathrm{O}\right]^{2}\left[\mathrm{O}_{2}\right]
\end{aligned}
$$

and the functions

$$
\alpha_{1}=\left(1+\frac{1}{2} \frac{k_{1 b}}{k_{2 f}} \frac{\left[\mathrm{CO}_{2}\right]}{\left[\mathrm{O}_{2}\right]}\right)^{-1}
$$

and

$$
\gamma=k_{5 f}[\mathrm{M}] / k_{2 f} .
$$

In the formulation, $M$ represents a third body, $[i]$ is the concentration of species $i$, and $k_{i f}$ and $k_{j b}$ denote the forward and backward rate constants of reactions $\mathrm{CO}+\mathrm{OH} \stackrel{1}{\rightleftharpoons} \mathrm{CO}_{2}+\mathrm{H}, \mathrm{O}_{2}+\mathrm{OH} \stackrel{2}{\rightleftharpoons} \mathrm{O}+\mathrm{OH}, \mathrm{O}_{2}+\mathrm{H}+\mathrm{M}$ $\stackrel{5}{\rightleftharpoons} \mathrm{HO}_{2}+\mathrm{M}$, and $\mathrm{HO}_{2}+\mathrm{OH} \stackrel{6}{\rightleftharpoons} \mathrm{H}_{2} \mathrm{O}+\mathrm{O}_{2}$. The values of the different reaction-rate constants used in the computations are given in Table 1. 
Table 1. Reaction-rate constants ${ }^{a}$

\begin{tabular}{llccc}
\hline Number & \multicolumn{1}{c}{ Reaction } & $A$ & $n$ & $E$ \\
\hline 1f & $\mathrm{CO}+\mathrm{OH} \rightarrow \mathrm{CO}_{2}+\mathrm{H}$ & $4.400 \mathrm{E}+06$ & 1.50 & -3.1 \\
1b & $\mathrm{H}+\mathrm{CO}_{2} \rightarrow \mathrm{OH}+\mathrm{CO}$ & $1.270 \mathrm{E}+09$ & 1.50 & 98.7 \\
2f & $\mathrm{O}_{2}+\mathrm{H} \rightarrow \mathrm{OH}+\mathrm{O}$ & $9.756 \mathrm{E}+13$ & 0.00 & 62.1 \\
2b & $\mathrm{OH}+\mathrm{O} \rightarrow \mathrm{O}_{2}+\mathrm{H}$ & $1.445 \mathrm{E}+13$ & 0.00 & 2.93 \\
3f & $\mathrm{H}_{2}+\mathrm{OH} \rightarrow \mathrm{H}_{2} \mathrm{O}+\mathrm{H}$ & $1.024 \mathrm{E}+08$ & 1.60 & 13.8 \\
3b & $\mathrm{H}_{2} \mathrm{O}+\mathrm{H} \rightarrow \mathrm{H}_{2}+\mathrm{OH}$ & $4.517 \mathrm{E}+08$ & 1.60 & 77.1 \\
$4 \mathrm{f}$ & $\mathrm{OH}+\mathrm{OH} \rightarrow \mathrm{H}_{2} \mathrm{O}+\mathrm{O}$ & $1.506 \mathrm{E}+09$ & 1.14 & 0.42 \\
$4 \mathrm{~b}$ & $\mathrm{O}+\mathrm{H}_{2} \mathrm{O} \rightarrow \mathrm{OH}+\mathrm{OH}$ & $1.559 \mathrm{E}+10$ & 1.14 & 71.7 \\
$5 f^{b}$ & $\mathrm{O}_{2}+\mathrm{H}+\mathrm{M} \rightarrow \mathrm{HO}+\mathrm{M}$ & $3.535 \mathrm{E}+18$ & -0.80 & 0 \\
$5 b^{b}$ & $\mathrm{HO}_{2}+\mathrm{M} \rightarrow \mathrm{O}_{2}+\mathrm{H}+\mathrm{M}$ & $5.058 \mathrm{E}+18$ & -0.80 & 196 \\
6f & $\mathrm{HO}_{2}+\mathrm{OH} \rightarrow \mathrm{H}_{2} \mathrm{O}+\mathrm{O}_{2}$ & $2.891 \mathrm{E}+13$ & 0.00 & -2.1 \\
6b & $\mathrm{O}_{2}+\mathrm{H} 2 \mathrm{O} \rightarrow \mathrm{OH}+\mathrm{HO}{ }_{2}$ & $3.069 \mathrm{E}+14$ & 0.00 & 300 \\
$\mathrm{~N} 1$ & $\mathrm{~N}_{2}+\mathrm{O} \rightarrow \mathrm{NO}+\mathrm{N}$ & $1.809 \mathrm{E}+14$ & 0.00 & 321 \\
$\mathrm{~N} 2$ & $\mathrm{~N}_{2}+\mathrm{OH} \rightarrow \mathrm{NO}+\mathrm{NH}$ & $1.834 \mathrm{E}+14$ & -0.23 & 409 \\
$\mathrm{~N} 3$ & $\mathrm{~N}_{2} \mathrm{O}+\mathrm{H} \rightarrow \mathrm{NO}+\mathrm{NH}$ & $1.455 \mathrm{E}+17$ & -0.45 & 146 \\
$\mathrm{~N} 4$ & $\mathrm{~N}_{2} \mathrm{O}+\mathrm{O} \rightarrow \mathrm{NO}+\mathrm{NO}$ & $6.620 \mathrm{E}+13$ & 0.00 & 111 \\
\hline
\end{tabular}

${ }^{a}$ Units are moles, cubic centimeters, seconds, kJoules, Kelvin.

${ }^{b}$ Third body collision efficiencies are $[\mathrm{M}]=0.6\left[\mathrm{H}_{2}\right]+0.4\left[\mathrm{~N}_{2}\right]+0.44\left[\mathrm{H}_{2} \mathrm{O}\right]+0.4\left[\mathrm{O}_{2}\right]+$ $1.5\left[\mathrm{co}_{2}\right]+3.0\left[\mathrm{CH}_{4}\right]+1.0[$ OTHERS $]$.

The steady-state approximations for $\mathrm{H}$ and $\mathrm{OH}$ obtained from Eqs. (2), (4), and (5) can be used in particular to express the CO-oxidation rate

$$
\omega_{\mathrm{II}}=k_{1 f}[\mathrm{CO}][\mathrm{OH}]-k_{1 b}\left[\mathrm{CO}_{2}\right][\mathrm{H}]
$$

in terms of the temperature and of the concentrations of $\mathrm{O}_{2}, \mathrm{CO}, \mathrm{CO}_{2}$, and $\mathrm{H}_{2} \mathrm{O}$.

Radicals are rapidly consumed in flames as they attack the fuel through reactions like $\mathrm{C}_{x} \mathrm{H}_{y}+\mathrm{H} \rightarrow \mathrm{C}_{x} \mathrm{H}_{y-1}+\mathrm{H}_{2}$ and $\mathrm{C}_{x} \mathrm{H}_{y}+\mathrm{OH} \rightarrow$ $\mathrm{C}_{x} \mathrm{H}_{y-1}+\mathrm{H}_{2} \mathrm{O}$, so that radicals and fuel can only coexist within the thin fuel-consumption layer. The depletion of radicals, which is responsible for the chemically frozen preheat region in premixed flames and for the chemically frozen fuel side in diffusion flames, is not directly reproduced if use is made of the fuel-consumption rate $\omega_{I}$ given in Eq. (1). To take into account this effect we follow the results of previous asymptotic analyses (Peters and Williams, 1987), which clearly show that radical depletion occurs where the fuel concentration $[\mathrm{F}]$ exceeds a characteristic value $[F]_{c}$. Guided by this finding, we choose here to implement 
the radical removal effect by multiplying the $\mathrm{OH}$ concentration calculated from Eq. (5) by a factor $f\left([\mathrm{~F}] /[\mathrm{F}]_{c}\right)$ that vanishes smoothly for increasing values of $[\mathbf{F}] /[\mathbf{F}]_{c}$. For instance, in methane combustion (Sánchez et al., 2000) the fuel-consumption step $\mathrm{CH}_{4}+\mathrm{H} \stackrel{7}{\rightarrow} \mathrm{CH}_{3}+\mathrm{H}_{2}$ was used to define the characteristic fuel concentration $\left[\mathrm{CH}_{4}\right]_{c}=$ $2(1-\gamma) k_{1 f}\left[\mathrm{O}_{2}\right] / k_{7}$ associated to radical removal, and the function $f=\left(1+\left[\mathrm{CH}_{4}\right] /\left[\mathrm{CH}_{4}\right]_{c}\right)^{-1}$ was selected for the cutoff multiplicative factor. Other functional forms $f\left([\mathrm{~F}] /[\mathrm{F}]_{c}\right)$ may be, however, more appropriate for higher hydrocarbons.

The reduced nitrogen chemistry used here is that presented in Sánchez et al. (2000), which accounts for both the thermal and nitrous oxide paths, but neglects the Fenimore contribution along with $\mathrm{NO}_{x}$ reburn. Rates of production of oxides of nitrogen in highly stretched diffusion flames depend strongly on the Fenimore mechanism (Hewson and Bollig, 1996), which can be included with reasonable accuracy only if account is taken of the formation and consumption of $\mathrm{C}_{2} \mathrm{H}_{2}$. Hence, if $\mathrm{NO}_{x}$ production in near-extinction diffusion flames is to be described accurately, the required fuel-oxidation mechanism must consider at least $\mathrm{C}_{2} \mathrm{H}_{2}$ as an additional species not in steady state, a description not attempted here. On the other hand, $\mathrm{NO}_{x}$ reburn may become important under conditions such that NO concentrations are large relative to radical concentrations (Hewson and Bollig, 1996), as occurs for instance in weakly strained diffusion flames. Therefore, the nitrogen chemistry used here, which accurately describes NO production in premixed flames, is only accurate in diffusion flames for an intermediate range of strain rates; it leads to overpredictions of NO emissions at low strain rates, where reburn is significant, and to underpredictions at high strain rates, where the Fenimore contribution dominates. Consideration of these additional contributions for increased accuracy certainly deserves further attention.

With all nitrogen species except $\mathrm{N}_{2}$ and $\mathrm{NO}$ assumed to be in steady state, and with NO-to- $\mathrm{NO}_{2}$ formation being omitted since it does not affect the ultimate $\mathrm{NO}_{x}$ emissions, the nitrogen chemistry reduces then to the single overall step (Sánchez et al., 2000)

$$
\mathrm{N}_{2}+\mathrm{O}_{2} \rightarrow 2 \mathrm{NO}
$$

with a rate given by

$$
\omega_{\mathrm{NI}}=k_{\mathrm{N} 1}[\mathrm{O}]\left[\mathrm{N}_{2}\right]+k_{\mathrm{N} 2}[\mathrm{OH}]\left[\mathrm{N}_{2}\right]+k_{\mathrm{N} 3}[\mathrm{H}]\left[\mathrm{N}_{2} \mathrm{O}\right]+k_{\mathrm{N} 4}[\mathrm{O}]\left[\mathrm{N}_{2} \mathrm{O}\right]
$$


in terms of the elementary reactions $\mathrm{N}_{2}+\mathrm{O} \stackrel{\mathrm{N} 1}{\rightarrow} \mathrm{NO}+\mathrm{N}, \mathrm{N}_{2}+\mathrm{OH} \stackrel{\mathrm{N} 2}{\longrightarrow}$ $\mathrm{NO}+\mathrm{NH}, \quad \mathrm{N}_{2} \mathrm{O}+\mathrm{H} \stackrel{\mathrm{N} 3}{\rightarrow} \mathrm{NO}+\mathrm{NH}$, and $\mathrm{N}_{2} \mathrm{O}+\mathrm{O} \stackrel{\mathrm{N} 4}{\rightarrow} 2 \mathrm{NO}$. In evaluating Eq. (14), the $\mathrm{H}, \mathrm{O}, \mathrm{OH}$, and $\mathrm{N}_{2} \mathrm{O}$ concentrations can be computed from their steady-state expressions, with that of nitrous oxide being given by

$$
\left[\mathrm{N}_{2} \mathrm{O}\right]=k_{\mathrm{N} 5 b}\left[\mathrm{~N}_{2}\right][\mathrm{O}][\mathrm{M}] /\left\{\left(k_{\mathrm{N} 3}+k_{\mathrm{N} 6}+k_{\mathrm{N} 7}\right)[\mathrm{H}]+k_{\mathrm{N} 5 f}[\mathrm{M}]+k_{\mathrm{N} 4}[\mathrm{O}]\right\} .
$$

Rate constants for reactions N1-N4, along with those of the additional $\mathrm{NO}_{2}$ consumption steps $\mathrm{N}_{2} \mathrm{O} \stackrel{\mathrm{N5}}{\rightleftharpoons} \mathrm{N}_{2}+\mathrm{O}, \mathrm{N}_{2} \mathrm{O}+\mathrm{H} \stackrel{\mathrm{N6}}{\longrightarrow} \mathrm{N}_{2} \mathrm{H}+\mathrm{O}$, and $\mathrm{N}_{2} \mathrm{O}+\mathrm{H} \stackrel{\mathrm{N} 7}{\rightleftharpoons} \mathrm{N}_{2}+\mathrm{OH}$ appearing in Eq. (15), can be found in Sánchez et al. (2000).

\section{SIMPLIFIED FORMULATION}

To facilitate numerical computations, it is advantageous to formulate the problem in terms of coupling functions, including passive scalars not affected by chemical reactions. The development uses linear combinations of the original conservation equations for energy and chemical species, a procedure introduced by Shvab (1948) and Zeldovich (1950) that reduces the number of differential equations to be integrated. We shall formulate the problem so that the chemical terms associated to each of the global steps of the reduced kinetics emerge only once in the resulting conservation equations, thereby enabling their isolated effect to be more easily tracked in computations. As shown in the work of Burke and Schumann (1928), this type of development is more strikingly effective in nonpremixed flames, for which the diffusion-controlled limit of fast chemical reactions can be adequately handled through use of the mixture fraction as a single nonreacting scalar.

Although the traditional methodology requires the assumption of equal diffusivities for all species involved in the coupling functions, such an assumption can be removed in diffusion flames as shown by Liñán and coworkers (see for instance Liñán and Williams, 1993; Sánchez et al., 1997; Bollig et al., 1998), yielding a description that accounts for different diffusivities of different species. Nevertheless, since molecular transport is secondary in the turbulent flows typically encountered in gas-turbine combustors, and since the molecular diffusivities of the species involved in the global reactions I, II, and NI are sufficiently close to 
the thermal diffusivity (except possibly for very heavy hydrocarbons), a unity-Lewis-number assumption will be used in the development below. Correspondingly, in writing the conservation equations we introduce the transport differential operator

$$
L()=\frac{\partial}{\partial t}[\rho()]+\nabla \cdot[\rho \bar{v}()]-\nabla \cdot\left[\rho D_{\mathrm{T}} \nabla()\right],
$$

where $\rho$ represents the density, $\bar{v}$ is the flow velocity, and $D_{\mathrm{T}}=\lambda /\left(\rho c_{p}\right)$ denotes the thermal diffusivity of the gas mixture, with $\lambda$ and $c_{p}$ representing its thermal conductivity and specific heat at constant pressure, the latter assumed to be independent of the mixture composition. Furthermore, the equations for chemical species are more easily expressed in terms of the variables $\Gamma_{i}=Y_{i} / W_{i}=[i] / \rho$, where $Y_{i}$ and $W_{i}$ denote, respectively, the mass fraction and molecular weight of chemical species $i$, while the energy balance is conveniently written in terms of the thermal enthalpy $h_{\mathrm{T}}=\int_{T_{\mathrm{ref}}}^{T} c_{p} \mathrm{~d} T$. With these definitions, the conservation equations become

$$
\begin{aligned}
L\left(\Gamma_{\mathbf{F}}\right) & =-\omega_{\mathrm{I}}, \\
L\left(\Gamma_{\mathrm{CO}}\right) & =x \omega_{\mathbf{I}}-\omega_{\mathrm{II}}, \\
L\left(\Gamma_{\mathrm{CO}_{2}}\right) & =\omega_{\mathrm{II}} \\
L\left(\Gamma_{\mathrm{H}_{2} \mathrm{O}}\right) & =\frac{y}{2} \omega_{\mathbf{I}} \\
L\left(\Gamma_{\mathrm{O}_{2}}\right) & =-\left(\frac{x}{2}+\frac{y}{4}\right) \omega_{\mathrm{I}}-\frac{1}{2} \omega_{\mathrm{II}}, \\
L\left(\Gamma_{\mathrm{N}_{2}}\right) & =\mathbf{0} \\
L\left(\Gamma_{\mathrm{NO}}\right) & =2 \omega_{\mathrm{NI}}, \\
L\left(\boldsymbol{h}_{\mathrm{T}}\right) & =\boldsymbol{q}_{\mathrm{I}} \omega_{\mathbf{I}}+q_{\mathrm{II}} \omega_{\mathrm{II}}-\nabla \cdot \bar{q}_{\mathrm{R}},
\end{aligned}
$$

where the overall heats of reaction are related to the enthalpies of formation per mole of species $i, h_{i}^{o}$, by the equations $q_{\mathrm{I}}=x h_{\mathrm{CO}}^{o}+\frac{y}{2} h_{\mathrm{H}_{2} \mathrm{O}}^{o}-h_{\mathrm{F}}^{o}$, and $q_{\mathrm{II}}=h_{\mathrm{CO}_{2}}^{o}-h_{\mathrm{CO}}^{o} \simeq 67700 \mathrm{cal} / \mathrm{mole}$. In the formulation, $\nabla \cdot \bar{q}_{\mathrm{R}}$ represents the radiative heat loss per unit volume. As corresponds to gas-turbine combustion conditions, a low-Mach-number approximation has been employed in writing Eq. (24), in which unsteady pressure variations have also been neglected. To completely describe the reacting flow field, Eqs. (17)-(24), supplemented by expressions for $\omega_{\mathrm{I}}, \omega_{\mathrm{II}}, \omega_{\mathrm{NI}}$, and $\bar{q}_{\mathrm{R}}$, must be integrated together with the continuity and momentum equations. 
For the computation of the gas-turbine combustion process the above equations must be accompanied with appropriate boundary conditions. Thus, in nonpremixed combustors different streams supply the fuel and the air, while premixed systems have a main feed stream that provides a reactive mixture of fuel and air. In addition, dilution air is typically supplied through secondary feed streams in all configurations. The concentrations of $\mathrm{CO}, \mathrm{CO}_{2}, \mathrm{H}_{2} \mathrm{O}$, and $\mathrm{NO}$ in all streams are zero. At the walls of the combustor, the nonpermeability condition yields $\nabla \Gamma_{i} \cdot \bar{n}=0$ as the appropriate boundary condition for all species, where $\bar{n}$ is the unit vector normal to the wall. The boundary condition for the thermal enthalpy at the walls is in general more complicated and may require the detailed consideration of the heat conduction problem in the wall. In particular, the simple boundary condition $\nabla h_{\mathrm{T}} \cdot \bar{n}=0$ applies when the walls can be assumed to be adiabatic, while the assumption of isothermal walls leads to the constant boundary condition $h_{\mathrm{T}}=h_{\mathrm{T} w}$.

A first quadrature can be obtained by combining linearly Eqs. (18)(20) to give

$$
L\left(\Gamma_{\mathrm{CO}}+\Gamma_{\mathrm{CO}_{2}}-\frac{2 x}{y} \Gamma_{\mathrm{H}_{2} \mathrm{O}}\right)=0 .
$$

Since $\Gamma_{\mathrm{CO}}=\Gamma_{\mathrm{CO}_{2}}=\Gamma_{\mathrm{H}_{2} \mathrm{O}}=0$ in the feed streams and $\nabla \Gamma_{i} \cdot \bar{n}=0$ at the wall, straightforward integration provides

$$
\Gamma_{\mathrm{H}_{2} \mathrm{O}}=\frac{y}{2 x}\left(\Gamma_{\mathrm{CO}}+\Gamma_{\mathrm{CO}_{2}}\right)
$$

as a replacement for Eq. 20. The selection of the remaining coupling relationships is different in premixed and nonpremixed systems, which are thereby treated separately below.

\section{Nonpremixed Systems}

Conditions in the fuel and air feed streams are denoted by the subscripts $f$ and $a$, respectively. Thus, $\Gamma_{\mathrm{O}_{2}}=\Gamma_{\mathrm{O}_{2} a} \simeq 0.23 / W_{\mathrm{O}_{2}}, \Gamma_{\mathrm{N}_{2}}=\Gamma_{\mathrm{N}_{2} a} \simeq$ $0.77 / W_{\mathrm{N}_{2}} h_{\mathrm{T}}=h_{\mathrm{T} a}$ are the boundary conditions in the air streams and $\Gamma_{\mathrm{F}}=\Gamma_{\mathrm{F} f}, \Gamma_{\mathrm{N}_{2}}=\Gamma_{\mathrm{N}_{2} f} h_{\mathrm{T}}=h_{\mathrm{T} f}$ are the corresponding boundary conditions in the fuel stream, where dilution with nitrogen is permitted.

Anticipating the limit of infinitely fast fuel consumption, it is convenient in nonpremixed systems to introduce the coupling function

$$
G=(x+y / 2) \Gamma_{\mathrm{F}}-2 \Gamma_{\mathrm{O}_{2}},
$$


together with the mixture fraction

$$
\begin{aligned}
Z & =\frac{(x+y / 2) \Gamma_{\mathrm{F}}-2\left(\Gamma_{\mathrm{O}_{2}}-\Gamma_{\mathrm{O}_{2} a}\right)-\Gamma_{\mathrm{CO}_{2}}}{(x+y / 2) \Gamma_{\mathrm{F} f}+2 \Gamma_{\mathrm{O}_{2} a}} \\
& =\frac{(2 x+y / 2) \Gamma_{\mathrm{F}}-2\left(\Gamma_{\mathrm{O}_{2}}-\Gamma_{\mathrm{O}_{2} a}\right)+\Gamma_{\mathrm{CO}}}{(2 x+y / 2) \Gamma_{\mathrm{F} f}+2 \Gamma_{\mathrm{O}_{2} a}}=\frac{\Gamma_{\mathrm{N}_{2}}-\Gamma_{\mathrm{N}_{2} a}}{\Gamma_{\mathrm{N}_{2} f}-\Gamma_{\mathrm{N}_{2} a}}
\end{aligned}
$$

and the normalized enthalpy

$$
H=\frac{h_{\mathrm{T}}-h_{\mathrm{T} a}+\left[q_{\mathrm{I}}-(x+y / 2) q_{\mathrm{II}}\right] \Gamma_{\mathrm{F}}+2 q_{\mathrm{II}}\left(\Gamma_{\mathrm{O}_{2}}-\Gamma_{\mathrm{O}_{2} a}\right)}{h_{\mathrm{T} f}-h_{\mathrm{T} a}+\left[q_{\mathrm{I}}-(x+y / 2) q_{\mathrm{II}}\right] \Gamma_{\mathrm{F} f}-2 q_{\mathrm{II}} \Gamma_{\mathrm{O}_{2} a}} .
$$

The problem then reduces to that of integrating

$$
\begin{aligned}
L\left(\Gamma_{\mathrm{F}}\right) & =-\omega_{\mathrm{I}}, \\
L(G) & =\omega_{\mathrm{II}}, \\
L(Z) & =\mathbf{0}, \\
L(H) & =-\nabla \cdot \bar{q}_{\mathrm{R}}, \\
L\left(\Gamma_{\mathrm{NO}}\right) & =2 \omega_{\mathrm{NI}}
\end{aligned}
$$

with boundary conditions $\Gamma_{\mathrm{F}}=\Gamma_{\mathrm{F} f}, G=(x+y / 2) \Gamma_{\mathrm{F} f}, Z=H=1$, and $\Gamma_{\mathrm{NO}}=0$ in the fuel stream and $\Gamma_{\mathrm{F}}=0, G=-2 \Gamma_{\mathrm{O}_{2} a}, Z=H=\Gamma_{\mathrm{NO}}=0$ in the air streams. At the walls, the variables $G$ and $Z$ satisfy $\nabla G \cdot \bar{n}=\nabla Z \cdot \bar{n}=\mathbf{0}$, while the boundary condition for $H$ is more complicated, reducing for instance to $\nabla H \cdot \bar{n}=0$ when adiabatic walls are considered, and to

$$
H=\frac{h_{\mathrm{T} w}-h_{\mathrm{T} a}+q_{\mathrm{I}} \Gamma_{\mathrm{F}}-q_{\mathrm{II}}\left(G+2 \Gamma_{\mathrm{O}_{2} a}\right)}{h_{\mathrm{T} f}-h_{\mathrm{T} a}+\left[q_{\mathrm{I}}-(x+y / 2) q_{\mathrm{II}}\right] \Gamma_{\mathrm{F} f}-2 q_{\mathrm{II}} \Gamma_{\mathrm{O}_{2} a}}
$$

in the case of isothermal walls. Note that when radiation is unimportant, the description of burners with adiabatic walls requires one less coupling function, since the solution of Eq. 34 is simply given in this limit by $H=Z$.

Under conditions such that the rate of fuel consumption is much faster than that of species transport, one can assume reaction I to be infinitely fast, retaining in the description the finite rate of $\mathrm{CO}$ oxidation. This limit removes the necessity to introduce a heuristic model for the fuel-consumption rate, since with fuel oxidation being infinitely fast Eq. 30 is replaced by the condition $\Gamma_{\mathrm{F}} \Gamma_{\mathrm{O}_{2}}=0$. The problem reduces then to that of integrating Eqs. (31)-(34) with the previously given 
boundary conditions. Since the reactants cannot coexist in this limiting case, the function $G$ is positive on the fuel side and negative on the oxidizer side, vanishing where the fuel-consumption layer is located. The concentrations of species and the thermal enthalpy are related to the coupling functions $G, Z$, and $H$ through simple expressions, different on the fuel and oxidizer side of the flame. For instance,

$$
\begin{aligned}
\Gamma_{\mathrm{F}} & =G /(x+y / 2), \\
\Gamma_{\mathrm{O}_{2}} & =0, \\
\Gamma_{\mathrm{CO}} & =\left[(2 x+y / 2) \Gamma_{\mathrm{F} f}+2 \Gamma_{\mathrm{O}_{2} a}\right] Z-(2 x+y / 2) G /(x+y / 2)-2 \Gamma_{\mathrm{O}_{2} a}
\end{aligned}
$$

for $G>0$ (fuel side), and

$$
\begin{aligned}
\Gamma_{\mathrm{F}} & =0, \\
\Gamma_{\mathrm{O}_{2}} & =-G / 2, \\
\Gamma_{\mathrm{CO}} & =\left[(2 x+y / 2) \Gamma_{\mathrm{F} f}+2 \Gamma_{\mathrm{O}_{2} a}\right] Z-G-2 \Gamma_{\mathrm{O}_{2} a}
\end{aligned}
$$

for $G<\mathbf{0}$ (oxidizer side). Similar piecewise linear expressions can be easily written for $\Gamma_{\mathrm{CO}_{2}}, \Gamma_{\mathrm{H}_{2} \mathrm{O}}, \Gamma_{\mathrm{N}_{2}}$, and $h_{\mathrm{T}}$ by combining the condition $\Gamma_{\mathrm{F}} \Gamma_{\mathrm{O}_{2}}=0$ with Eqs. (26), (28), and (29). In this limit, $\mathrm{CO}$ oxidation occurs only for $G<0$, since on the fuel side radical concentrations vanish because of infinitely fast radical removal at the fuel-consumption layer.

\section{Premixed Systems}

Different coupling functions must be written for the numerical description of premixed systems. Because of partial mixing between the fuel and the air, the conditions in the main feed stream in premixed combustors are in general nonuniform. Correspondingly, at the entrance of the combustor we find the reactant distributions $\Gamma_{\mathrm{F}}=\Gamma_{\mathrm{Fe}}$ and $\Gamma_{\mathrm{O}_{2}}=\Gamma_{\mathrm{O}_{2}}$ e, together with the nitrogen distribution $\Gamma_{\mathrm{N}_{2}}=\Gamma_{\mathrm{N}_{2} e}$ and the thermalenthalpy distribution $h_{\mathrm{T}}=h_{\mathrm{Te}}$. The local values of $\Gamma_{\mathrm{Fe}}, \Gamma_{\mathrm{O}_{2} e}$, and $\Gamma_{\mathrm{N}_{2} e}$ are related to the local equivalence ratio $\phi_{e}$ by the equations

$$
\frac{\Gamma_{\mathrm{Fe}}}{W_{\mathrm{F}}^{-1}}=1-\frac{\Gamma_{\mathrm{O}_{2} e}}{\Gamma_{\mathrm{O}_{2} a}}=1-\frac{\Gamma_{\mathrm{N}_{2} e}}{\Gamma_{\mathrm{N}_{2} a}}=\frac{\phi_{e}}{\phi_{e}+(x+y / 4) /\left(W_{\mathrm{F}} \Gamma_{\mathrm{O}_{2} a}\right)},
$$

where it is been assumed that, as typically occurs in applications, pure fuel is mixed with air to generate the reactant mixture. On the other 
hand, in the secondary feed streams, $\Gamma_{\mathrm{O}_{2}}=\Gamma_{\mathrm{O}_{2} a}, \Gamma_{\mathrm{N}_{2}}=\Gamma_{\mathrm{N}_{2} a}, \Gamma_{\mathrm{F}}=0$, and $h_{\mathrm{T}}=h_{\mathrm{T} a}$.

The relationship between the fuel and air content in the feed stream displayed in Eq. 38 motivates the introduction of the passive scalar

$$
\begin{aligned}
X & =\frac{\Gamma_{\mathrm{F}}+\left(\Gamma_{\mathrm{CO}}+\Gamma_{\mathrm{CO}_{2}}\right) / x}{W_{\mathrm{F}}^{-1}} \\
& =\frac{\Gamma_{\mathrm{O}_{2} a}-\Gamma_{\mathrm{O}_{2}}-\left(\frac{1}{2}+\frac{y}{4 x}\right) \Gamma_{\mathrm{CO}}-\left(1+\frac{y}{4 x}\right) \Gamma_{\mathrm{CO}_{2}}}{\Gamma_{\mathrm{O}_{2} a}} \\
& =\frac{\Gamma_{\mathrm{N}_{2} a}-\Gamma_{\mathrm{N}_{2}}}{\Gamma_{\mathrm{N}_{2} a}}
\end{aligned}
$$

which, together with the normalized enthalpy

$$
\bar{H}=\frac{h_{\mathrm{T}}-h_{\mathrm{T} a}-\left(q_{\mathrm{I}} / x\right) \Gamma_{\mathrm{CO}}-\left(q_{\mathrm{I}} / x+q_{\mathrm{II}}\right) \Gamma_{\mathrm{CO}_{2}}}{h_{\mathrm{T} a}},
$$

conform the required coupling functions for the description of premixed systems. The problem reduces to that of integrating

$$
\begin{aligned}
L\left(\Gamma_{\mathrm{F}}\right) & =-\omega_{\mathbf{I}}, \\
L\left(\Gamma_{\mathrm{CO}_{2}}\right) & =\omega_{\mathrm{II}}, \\
L(X) & =\mathbf{0} \\
L(\bar{H}) & =-\nabla \cdot \bar{q}_{\mathrm{R}}, \\
L\left(\Gamma_{\mathrm{NO}}\right) & =2 \omega_{\mathrm{NI}}
\end{aligned}
$$

with boundary conditions $\Gamma_{\mathrm{F}} W_{\mathrm{F}}=X=\phi_{e} /\left[\phi_{e}+(x+y / 4) /\left(W_{\mathrm{F}} \Gamma_{\mathrm{O}_{2} a}\right)\right]$, $\Gamma_{\mathrm{CO}_{2}}=\Gamma_{\mathrm{NO}}=0$, and $\bar{H}=\bar{H}_{e}=\left(h_{\mathrm{T} e}-h_{\mathrm{T} a}\right) / h_{\mathrm{T} a}$ in the main feed stream, and $\Gamma_{\mathrm{F}}=\Gamma_{\mathrm{CO}_{2}}=\Gamma_{\mathrm{NO}}=X=\bar{H}=0$ in the secondary feed streams. At the walls, the variable $X$ satisfies $\nabla X \cdot \bar{n}=\mathbf{0}$, while the boundary condition for $\bar{H}$ is more complicated, reducing to $\nabla \bar{H} \cdot \bar{n}=0$ when adiabatic walls are considered and to $\bar{H}=\left[\left(h_{\mathrm{T} w}-h_{\mathrm{T} a}\right)-q_{\mathrm{I}}\left(X / W_{\mathrm{F}}-\Gamma_{\mathrm{F}}\right)-q_{\mathrm{II}} \Gamma_{\mathrm{CO}_{2}}\right] /$ $h_{\mathrm{T} a}$ in the case of isothermal walls.

Further simplifications arise under more restrictive conditions. For instance, when the reactants are perfectly mixed in the main feed stream, then the associated constant boundary values of $X$ and $\bar{H}$ at the entrance of the combustor can be used to redefine normalized variables $X^{*}=X / X_{e}$ and $H^{*}=\bar{H} / \bar{H}_{e}$, so that $X^{*}=H^{*}=1$ in the main stream. $A$ further simplification arises when adiabatic walls are considered and 
radiation is neglected, a case for which Eqs. 45 can be replaced by $\bar{H}=\bar{H}_{e} X / X_{e}$, which in turn reduces to $\bar{H}=0$ if $h_{\mathrm{T} e}=h_{\mathrm{T} a}$.

\section{DESCRIPTION OF METHANE-AIR FLAMES}

The reduced kinetics proposed here, and its associated formulations in terms of coupling functions, are now tested through comparisons with results of detailed-chemistry computations. Methane is the simplest hydrocarbon, and therefore, the present paper addresses methane-air flames as a first validation step. Calculations of freely propagating premixed flames and also of counterflow diffusion flames are performed. The "FlameMaster" code (Pitsch and Bollig, 1994) is utilized in the detailed-chemistry calculations, which incorporate also a detailed transport description. Although these preliminary tests show excellent agreement between the results of the reduced mechanism and those of the detailed chemistry, further comparisons including unsteady threedimensional effects would be necessary to guarantee the validity of the proposed kinetics. More work is also required to ascertain the accuracy with which the mechanism describes combustion of more complex hydrocarbons.

\section{Freely Propagating Planar Flames}

Calculations of planar premixed flames were performed with the threestep reduced mechanism and also with the detailed mechanism described elsewhere (Sánchez et al., 2000). The simplified conservation Eqs. (41)(45) were employed in the reduced-kinetic calculations, which involve therefore a unity-Lewis-number approximation for all species appearing in the global reactions I, II, and NI. Only results of freely propagating flames will be presented here. More extensive calculations of methane premixed flames addressing in particular the effect of stretch and the associated phenomenon of strain-induced extinction can be found in our earlier work (Sánchez et al., 2000).

A quantity of particular interest in premixed combustion is the flame propagation velocity $u_{l}$. The ability to describe accurately this quantity emerges as a necessary requirement for the reduced kinetics. The results exhibited in Sánchez et al., (2000) indicate that, with the values for the fuel-consumption reaction-rate parameters given previously below Eq. (1), the two-step fuel-oxidation mechanism reproduces flame 
propagation velocities with errors smaller than $20 \%$ over a wide range of conditions. Furthermore, this accuracy extends to conditions outside the range for which the mechanism was originally derived $(p>5$ bar, $T_{u}>500 \mathrm{~K}$, and $\left.\phi<1\right)$. To illustrate this feature of the mechanism, the variation with pressure of the laminar burning velocity $u_{l}$ of a stoichiometric methane-air mixture at initial temperature $T_{u}=298 \mathrm{~K}$ is plotted in Figure 1. Results of calculations with the reduced kinetics are compared with detailed-chemistry computations and also with experimental measurements (Warnatz, 1988). As can be seen, over the range of pressures considered ( 2 bar $<p<40$ bar) the reduced kinetics reproduces with excellent accuracy $u_{\text {l, }}$, with somewhat larger errors appearing only at the highest pressures investigated. It is worth remarking that the activation energy of the fuel-consumption step is sufficiently large to enable the asymptotic analysis of the flame structure, as shown by Liñán et al. (1998). The analysis provides a set of algebraic equations

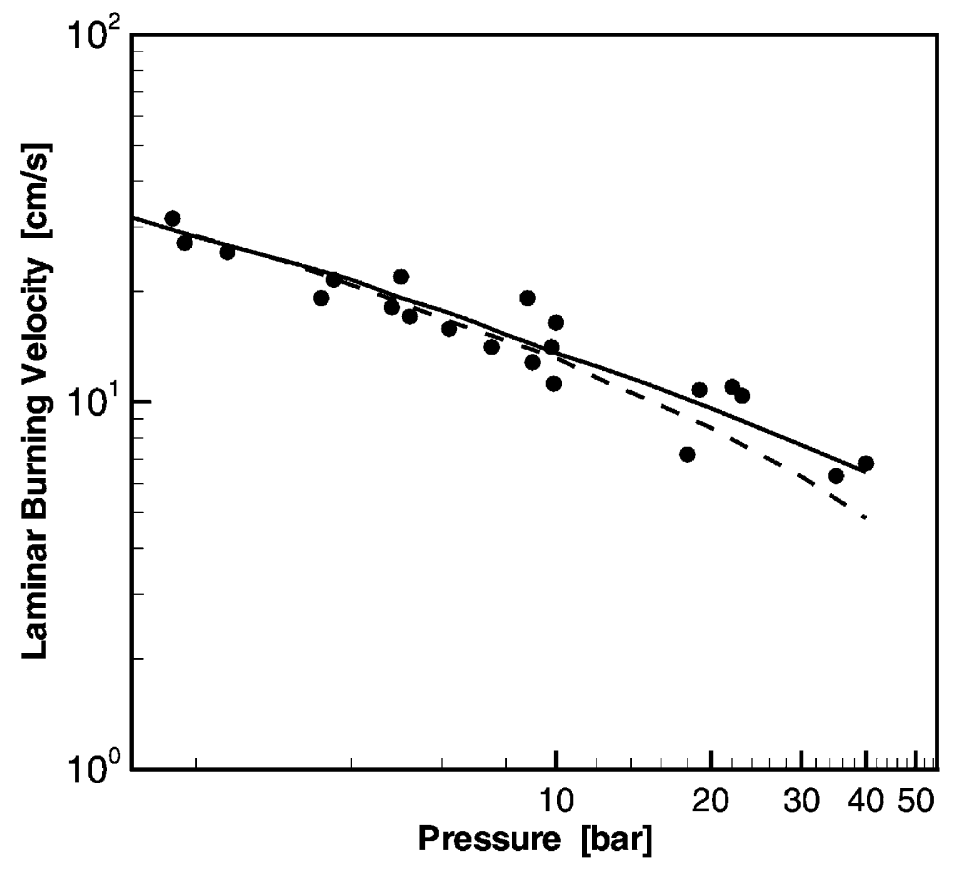

Figure 1. The variation with pressure of the laminar burning velocity $u_{l}$ for a stoichiometric mixture of methane and air at $T_{u}=298 \mathrm{~K}$ as obtained from experiments (dots), from detailed-chemistry computations (solid line), and from the reduced kinetics (dashed line). 

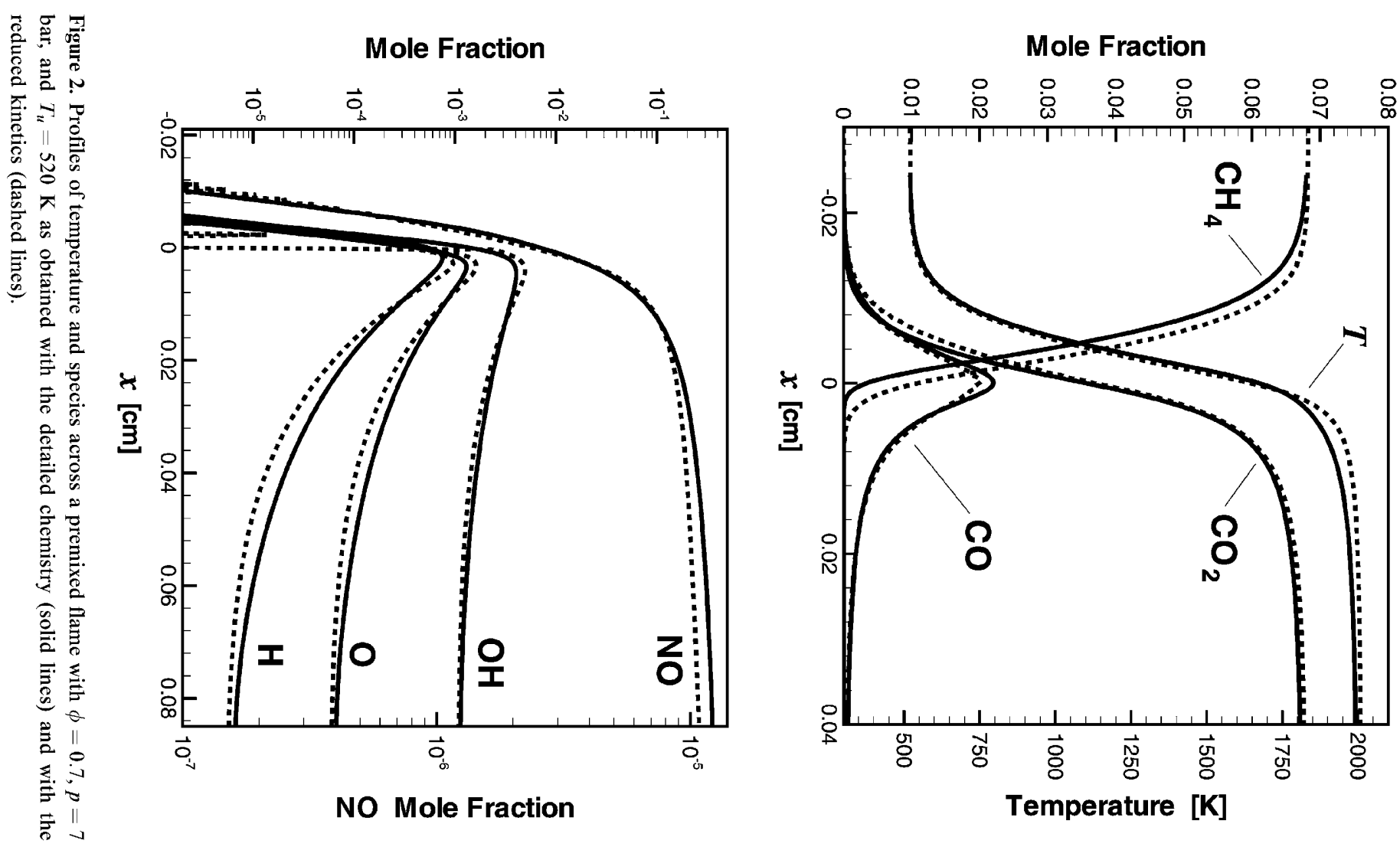
that determine in particular the value of $u_{l}$ in terms of the different parameters of the proposed kinetic mechanism. However, the structure of this implicit solution is complex, and does not permit one to extract simple explicit dependences of $u_{l}$ on $\phi, T_{a}$, and $p$.

The reduced kinetics also describes accurately the inner structure of premixed flames. This is illustrated in Figure 2, where we plot profiles of species and temperature for a nonradiating planar flame, with $x$ denoting the distance across the flame from the location where the $\mathrm{CO}$ concentration peaks. For the conditions selected $(\phi=0.7, p=7$ bar, and $T_{u}=520 \mathrm{~K}$ ) the burning velocity calculated with the detailed mechanism $u_{l}=30.19 \mathrm{~cm} / \mathrm{s}$ differs only slightly from the value $u_{l}=28.01 \mathrm{~cm} / \mathrm{s}$ calculated with the reduced kinetics.

As can be seen, satisfactory agreement is found for profiles of main species and temperature, as well as for those of all relevant intermediates. In particular, with the steady-state approximations employed, not only the peak values for carbon monoxide and radicals but also their downstream evolutions toward equilibrium are well reproduced. Furthermore, the anticipated failure of the steady-state assumption for radicals within the fuel-consumption layer is seen to have only a marginal effect. The plot also reveals that NO production is accurately described with the one-step mechanism proposed here. Both the initial region of rapid NO production associated with superequilibrium radical concentrations and the post-flame NO-production rate are adequately reproduced.

\section{Counterflow Diffusion Flames}

The proposed kinetics was also applied to the calculation of undilute methane-air diffusion flames in the planar counterflow mixing layer. The character of the solution that emerges depends on the existing strain rate $a$, defined here as the velocity gradient in the approaching air stream. The solution admits a self-similar description in terms of the distance $y$ from the stagnation plane. The simplified conservation equations corresponding to this flow configuration are described, for instance, in Peters and Rogg (1993). For the detailed-chemistry calculations, the fuel-oxidation chemistry presented in Peters and Rogg (1993) was used, whereas NO production was calculated from a detailed scheme of 192 reactions and 14 nitrogen-containing species that includes the reactions presented in Sánchez et al. (2000) together with additional reactions corresponding to the Fenimore and reburn mechanisms. 
The calculations with the reduced kinetics are performed in the limit of infinitely fast fuel consumption $\left(\omega_{\mathrm{I}}=\infty\right)$. With this simplifying assumption, strain-induced extinction cannot be described. Despite this limitation, the results below indicate that this limit is applicable with reasonable accuracy over several orders of magnitude in strain rate. Extensions of the calculations to include a finite fuel-consumption rate are left for future research.

For the computations, conditions of pressure $p=18$ bar and of boundary temperatures $T_{f}=T_{a}=800 \mathrm{~K}$ are selected as representative of gas-turbine combustion. Strain rates varying over many orders of magnitude were computed, with the maximum value $a \simeq 16000 \mathrm{~s}^{-1}$ considered being that at which the flame calculated with detailed chemistry extinguishes. To illustrate the accuracy of the proposed description, profiles of temperature and species corresponding to an intermediate strain rate $a=100 \mathrm{~s}^{-1}$ are plotted in Figure 3. As can be seen, good agreement is found for all profiles, with the largest departures being those associated to radical profiles. In particular, the reduced kinetic description reproduces accurately the CO profile. Similar agreement is found for all strain rates investigated, with errors increasing as extinction is approached, where peak values are overpredicted by as much as $40 \%$. The peak values and the shape of the radical profiles are also reasonably well reproduced. The sharp decrease observed on the fuel side is associated to the infinitely fast fuel consumption rate used in the reduced kinetic calculations. Some improvement in the description can be expected should the finite rate given in Eq. (1) be used in the computations. On the other hand, although excellent accuracy is found for the NO profile in this case, the agreement found for both smaller and larger strain rates is much less satisfactory as discussed below.

The global effect of strain on the flame can be adequately measured through integrated reaction rates, two examples being the fuel burning rate per unit flame surface $m_{\mathrm{F}}=\int_{-\infty}^{\infty} \omega_{\mathrm{F}} \mathrm{d} y$ and the $\mathrm{CO}$ production rate per unit flame surface $m_{\mathrm{CO}}=\int_{-\infty}^{\infty} \omega_{\mathrm{CO}} \mathrm{d} y$. In the formulation, $\omega_{\mathrm{F}}$ and $\omega_{\mathrm{CO}}$ represent the local rates of fuel consumption and $\mathrm{CO}$ production (in moles per unit volume per unit time). When use is made of the detailed chemistry scheme, the contribution of a large number of elementary reactions must be evaluated to compute these rates. On the other hand, for the reduced kinetics with infinitely fast fuel consumption, the fuel burning rate $m_{\mathrm{F}}$ equals the fuel mole flux $-\rho D_{\mathrm{T}} \mathrm{d} \Gamma_{\mathrm{F}} / \mathrm{d} y$ at the fuel-consumption layer, which can be easily computed from the derivarite 

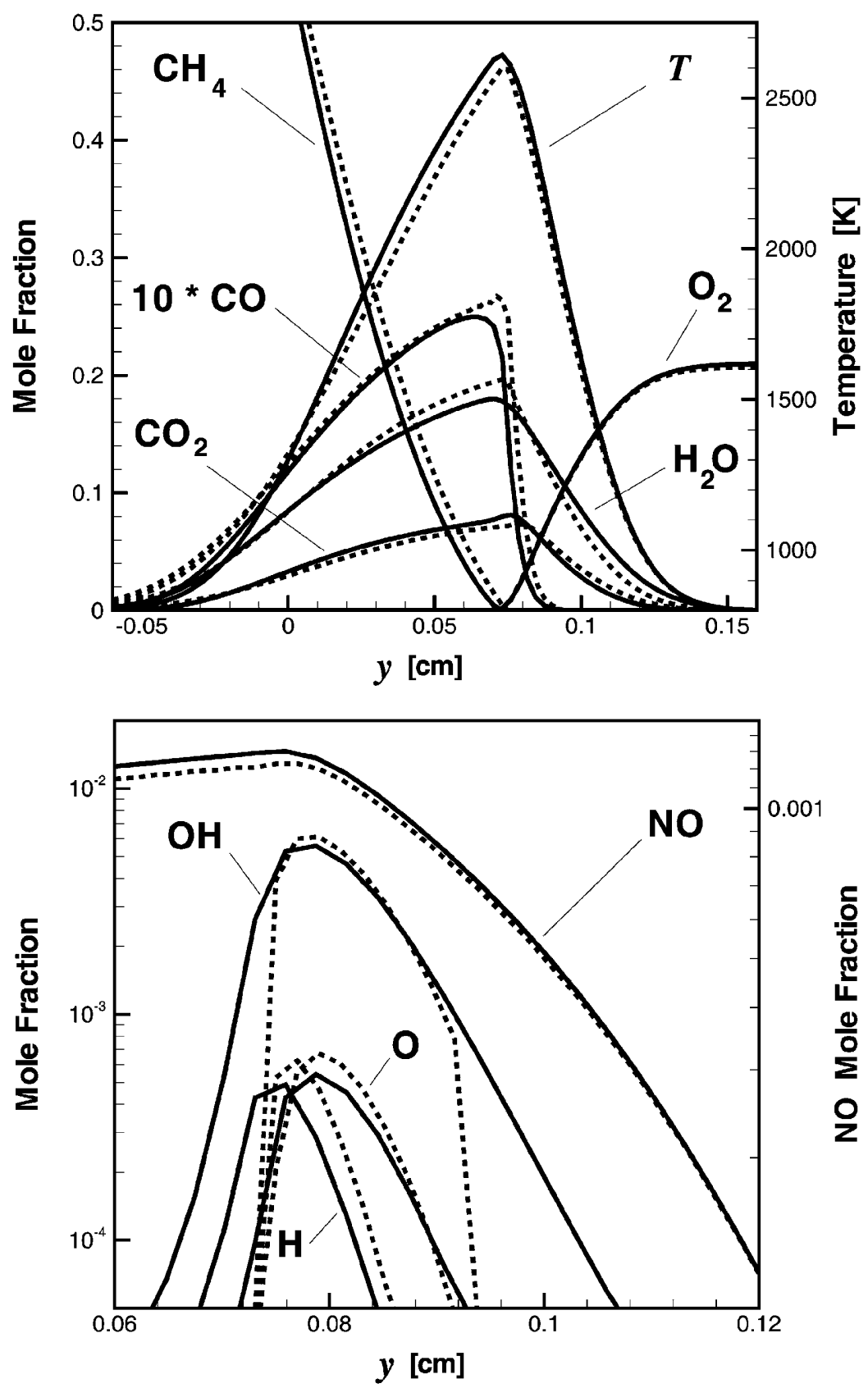

Figure 3. Profiles of temperature and species across an undiluted counterflow methane-air flame with $a=100 \mathrm{~s}^{-1}$ and $p=18$ bar and with boundary temperatures $T_{f}=T_{a}=800 \mathrm{~K}$ as obtained with the detailed chemistry (solid lines) and with the reduced kinetics (dashed lines). 
of the coupling function $G$ [defined above in Eq. (27)], while the CO production rate reduces to $m_{\mathrm{CO}}=m_{\mathrm{F}}-\int_{-\infty}^{\infty} \omega_{\mathrm{II}} \mathrm{d} y$.

The variation with strain rate of $m_{\mathrm{F}}$ and $m_{\mathrm{CO}}$ for the flame investigated here is exhibited in Figure 4. As can be seen, the simplified kinetics yields very accurate predictions for these two quantities until extinction is reached. As previously mentioned, with the assumption of infinitely fast fuel consumption extinction cannot be reproduced, so that for $a>16000 \mathrm{~s}^{-1}$ the reduced kinetics still gives a flame with increasing reaction rates for increasing $a$. Note that, in spite of this severe limitation of the model, the results reveal that $\mathrm{CO}$ emissions can be computed with errors smaller than $30 \%$ over three orders of magnitude in strain rate.

Emissions of oxides of nitrogen are usually measured in terms of the emission index

$$
(E I)_{\mathrm{NO}}=\frac{W_{\mathrm{NO}}}{W_{\mathrm{F}}} \frac{\int_{-\infty}^{\infty} \omega_{\mathrm{NO}} \mathrm{d} y}{\int_{-\infty}^{\infty} \omega_{\mathrm{F}} \mathrm{d} y} \times 10^{3}
$$

defined here as the grams of NO produced per kilogram of fuel consumed. Figure 5 shows the variation of this quantity with strain as obtained with the one-step nitrogen chemistry and with the detailed kinetics. Although qualitative agreement can be observed between the two sets of calculations, large quantitative discrepancies appear at low strain rates and also as extinction is approached.

At low strain rates, NO concentrations are large and radical levels are very low, so that the contribution of NO reburn becomes nonnegligible. Since the reduced kinetics neglects this effect, considerable overpredictions of $(E I)_{\text {NO }}$ are clearly observable for $a \lesssim 100 \mathrm{~s}^{-1}$. On the other hand, the Fenimore contribution, which is absent in the reduced chemistry, dominates NO production as the temperature decreases for increasing $a$. As a result, unacceptable underpredictions emerge for $a \gtrsim 5000 \mathrm{~s}^{-1}$. The range of validity of the simplified nitrogen chemistry is therefore restricted to strain rates on the order of $a \simeq 500 \mathrm{~s}^{-1}$. Clearly, predictions of oxides of nitrogen in diffusion flames near equilibrium and also near extinction require a more complete model for NO production than that considered here. It is, however, worth mentioning that, for the combustion conditions typically encountered in gas-turbine combustors, residence times are of the order of a few milliseconds and, consequently, strain rates can be anticipated to be in the range where our proposed nitrogen chemistry yields acceptable predictions of NO emissions. 

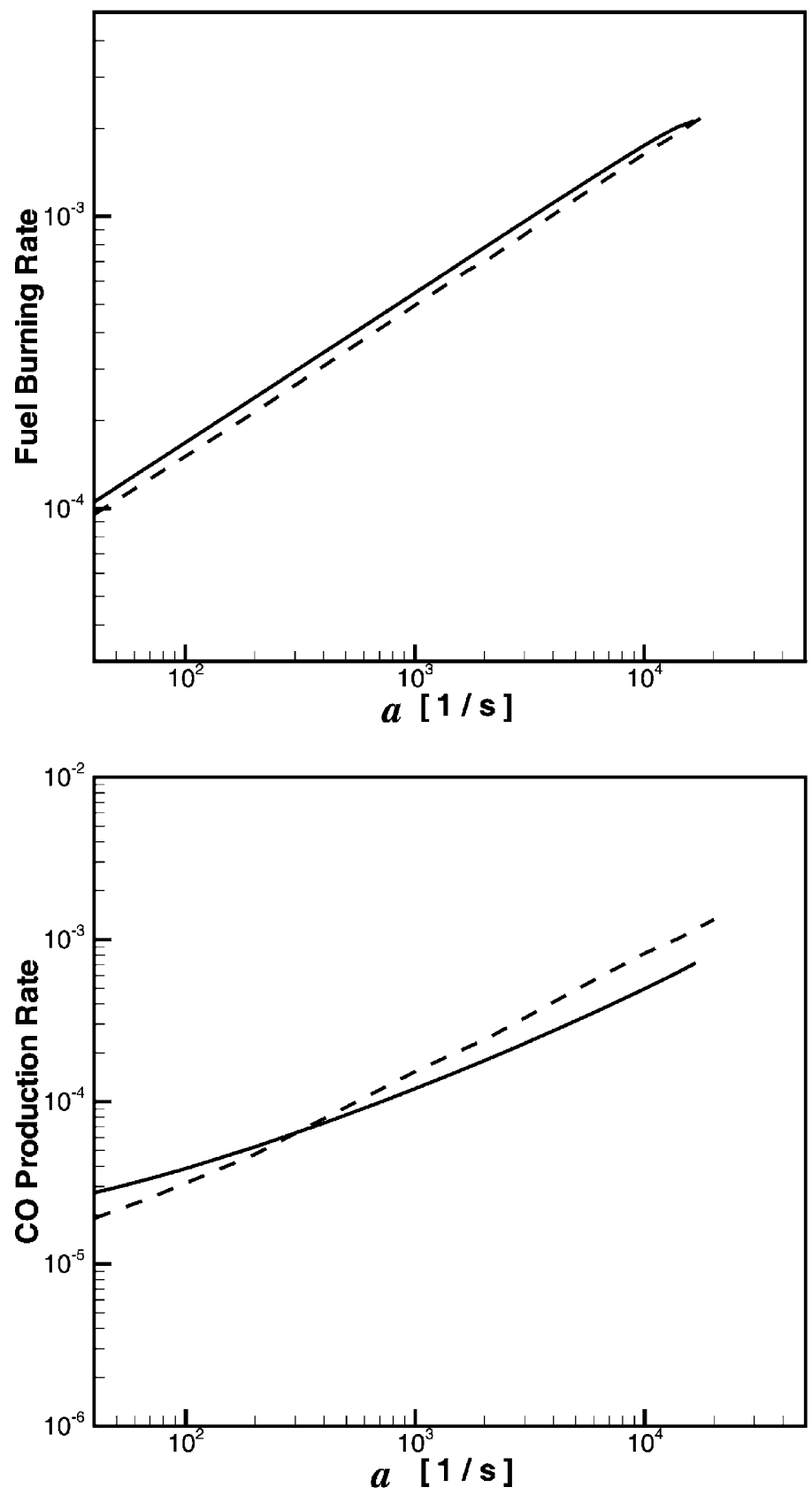

Figure 4. The variation with strain rate of the fuel burning and $\mathrm{CO}$ production rates per unit flame surface (in $\mathrm{gr} / \mathrm{cm}^{2} / \mathrm{s}$ ) for an undiluted counterflow methane-air flame with $p=18$ bar and with boundary temperatures $T_{f}=T_{a}=800 \mathrm{~K}$ as obtained with the detailed chemistry (solid lines) and with the reduced kinetics (dashed lines). 


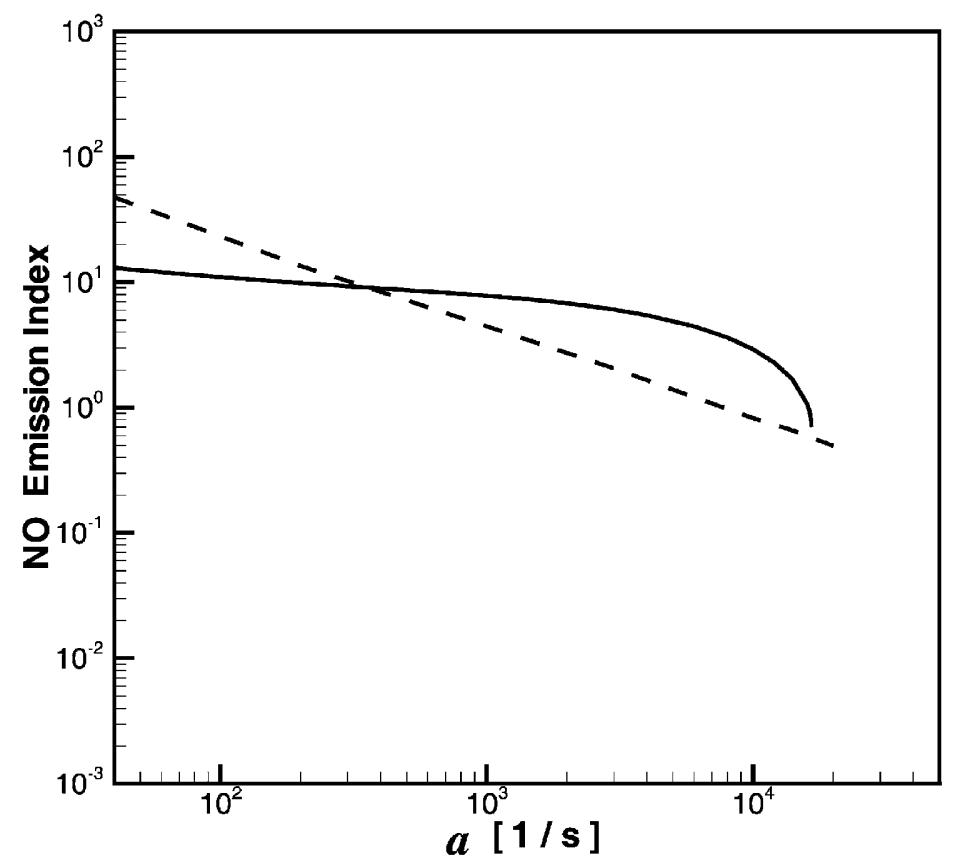

Figure 5. The variation with strain rate of the NO emission index for an undiluted counterflow methane-air flame with $p=18$ bar and with boundary temperatures $T_{f}=T_{a}=800 \mathrm{~K}$ as obtained with the detailed chemistry (solid lines) and with the reduced kinetics (dashed lines).

\section{CONCLUDING REMARKS}

The present paper employs a reduced scheme specifically derived for describing $\mathrm{CO}$ and $\mathrm{NO}$ emissions in gas-turbine combustion. The proposed mechanism comprises two steps for hydrocarbon oxidation and an additional step for NO production. As a preliminary step to facilitate computations with the proposed kinetics, simplified formulations of the conservation equations in terms of coupling functions are derived. Methane-air laminar flames are then computed with the resulting three-step mechanism, and the results are compared with detailedchemistry calculations. The computations performed here supplement those presented by Sánchez et al. (2000), further validating the reduced kinetics in the case of premixed flames. Preliminary results concerning diffusion flames indicate that the limit of infinitely fast fuel consumption, and its associated simplified formulation, is applicable with reasonable 
accuracy over several orders of magnitude in strain rate. The description of extinction phenomena, which is done for stretched premixed flames in our previous paper (Sánchez et al., 2000), requires consideration of a finite rate of fuel consumption. This issue is left for future work, which should also address combustion of more complex hydrocarbons along with unsteady and curvature effects. The results also indicate that the NO reburn and the Fenimore production are significant for some regimes of nonpremixed combustion. Further work to incorporate these effects is in progress. Although the results presented above indicate that the assumption of unity Lewis number, used in the reduced-chemistry computations, is a valid approximation in methane combustion for all species out of steady state, nonunity-Lewis-number effects may, however, become significant in the case of heavier fuels.

Bollig, M., Liñán, A., Sánchez, A.L., and Williams, F.A. (1998) A simplified approach to the numerical description of methane-air diffusion flames. Proc. Combust. Inst., 27, 595.

Bui-Pham, M., Seshadri, K., and Williams, F.A. (1992) The asymptotic structure of premixed methane-air flames with slow $\mathrm{CO}$ oxidation. Combust. Flame, 89, 343.

Burke, S.P. and Schumann, T.E.W. (1928) Diffusion flames. Ind. Eng. Chem., 20, 998.

Hewson, J. and Bollig, M. (1996) Reduced mechanisms for $\mathrm{NO}_{x}$ emissions from hydrocarbon diffusion flames. Proc. Combust. Inst., 26, 2171.

Li, S.C., Williams, F.A., and Gebert, K. (1999) A simplified, fundamentally based method for calculating $\mathrm{NO}_{x}$ emissions in lean premixed combustors. Combust. Flame, 119, 367.

Liñán, A., Bollig, M., Sánchez, A.L., and Lázaro, B. (1998) Reduced Kinetic Mechanisms for Modelling LPP Combustion in Gas Turbines, RTO Meeting Proceedings 14, Gas Turbine Engine Combustion, Emissions and Alternative Fuels, NATO. Papers presented at the Applied Vehicle Technology Panel (AVT) Symposium, Lisbon, Portugal, 12-16 October.

Liñán, A. and Williams, F.A. (1993) Fundamental Aspects of Combustion, 1st ed., Oxford University Press, New York, pp. 144-146.

Peters, N. and Rogg, B. (1993) Reduced Kinetic Mechanisms for Applications in Combustion Systems Vol. m15 of Lecture Notes in Physics, Springer-Verlag, Heidelberg.

Peters, N. and Williams, F.A. (1987) The asymptotic structure of stoichiometric methane-air flames. Combust. Flame, 68, 185. 
Pitsch, H. and Bollig, M. (1994) FlameMaster, A Computer Code for Homogeneous and One-Dimensional Laminar Flame Calculations, Institut für Technische Mechanik, RWTH, Aachen.

Sánchez, A.L., Lépinette, A., Bollig, M., Liñán, A., and Lázaro, B. (2000) The reduced kinetic description of lean premixed combustion. Combust. Flame, $123,436$.

Sánchez, A.L., Liñán, A., and Williams F.A. (1997) A generalized BurkeSchumann formulation for hydrogen-oxygen diffusion flames maintaining partial equilibrium of the shuffle reactions. Combust. Sci. Technol., 123, 317.

Shvab, V.A. (1948) Svyaz' mezhdu temperaturnymi i skorostnymi polyami gazovogo fakela (The relationship between the temperature and the velocity fields in a gaseous flame). In Isseledovanie Protsessov Goreniya Natural'nogo Topliva (Research on Combustion Processes in Natural Fuel) Gosenergoizdat, Moscow, Leningrad.

Warnatz, J. (1988) Detailed studies of combustion chemistry. Proceedings of the Contractors' Meeting on EC Combustion Research, EC, Bruxelles, p. 172.

Zeldovich, Y.B. (1950) K teorii goreniya neperemeshannykh gasov (On the theory of combustion of unmixed gases). Zhur. Tekhn. Fiz., 19, 1199. 